finishing diets. To further evaluate the microbial community involved in methane emission and performance, correlation analysis was performed using microbial community composition and performance parameters. This analysis identified many OTUs correlated with methane emission, performance, and intake. This study demonstrates that certain members of the rumen microbial community have a profound effect on animal performance and methane emission.

Key Words: Interactions, methane, microbial community

doi: $10.2527 /$ msasas2016-114

\section{Effects of stocking density on finishing pig growth}

performance. L. L. Thomas*, R. D. Goodband, M. D. Tokach, J. M. DeRouchey, J. C. Woodworth, S. S. Dritz, Kansas State University, Manhattan.

A total of 405 pigs (PIC $327 \times 1050$ ) from 2 consecutive finishing groups (group 1 initially $66 \pm 1.8 \mathrm{~kg} \mathrm{BW}$, group 2 initially $61 \pm 2.5 \mathrm{~kg} \mathrm{BW}$ ) were used to examine the effects of stocking density on finishing pig growth performance. Pens of pigs were balanced by initial BW and randomly allotted to 1 of 3 treatments with either 7 or 8 replications per treatment (group 1 and 2, respectively). Pens were stocked with 9 pigs, and adjustable gates provided treatments that allowed for $0.84,0.74$, or $0.65 \mathrm{~m}^{2}$ per pig. All pigs were fed the same diets fed in 3 phases. Pigs were provided with $7.91 \mathrm{~cm}$ of feeder space per pig. In both studies, as stocking density decreased, ADG and ADFI increased (linear, $P<0.019$ ), but there was no difference in G:F. As a result, final weight was 3.9 and $5.3 \mathrm{~kg}$ greater (linear, $P \leq 0.005$ ) in groups 1 and 2 , respectively, when comparing the lowest to the highest stocking density treatments. When comparing growth performance to a suggested required $k$-value of 0.0336 , performance should have been affected above 122,102 , and $83 \mathrm{~kg}$ at $0.84,0.74$, and $0.65 \mathrm{~m}^{2}$ per pig. In group 1 , performance should not have been affected until after $109.0 \mathrm{~kg}, 94.0 \mathrm{~kg}$, and $80.3 \mathrm{~kg}$ for the $0.84,0.74$, and $0.65 \mathrm{~m}^{2}$ per pig treatments, respectively. However, in group 1 even after d 14 (less than $74.5 \mathrm{~kg}$ ), negative effects of increased stocking density were observed on ADFI (linear, $P<0.08$ ). In group 2 , performance should not have been affected until after $118 \mathrm{~kg}, 87 \mathrm{~kg}$, and $74 \mathrm{~kg}$ for the $0.84,0.74$, and $0.65 \mathrm{~m}^{2}$ per pig treatments. Similar to group 1 , feed consumption and consequently ADG decreased linearly $(P \leq 0.033)$ as stocking density increased, before pigs reached the $k$-value that should have influenced performance. Overall, this study indicates that increasing stocking density resulted in poorer ADG driven by a reduction in ADFI and the accepted $k$-value of 0.0336 might underestimate the impact of increased stocking density.

Key Words: finishing pig, space allowance, stocking density

doi: $10.2527 /$ msasas2016-115
Table 115.

\begin{tabular}{lccccccc}
\hline \multirow{2}{*}{$\begin{array}{c}\text { Group } 2 \\
\text { Item }\end{array}$} & \multicolumn{3}{c}{ Space allocation per pig, $\mathrm{m}^{2}$} & & \multicolumn{2}{c}{ Probability, $P<$} \\
\cline { 2 - 4 } \cline { 7 - 8 } & 0.84 & 0.74 & 0.65 & & SEM & Linear & Quadratic \\
\hline $\begin{array}{l}\text { Pens, no. } \\
\text { d 0 to 77 }\end{array}$ & 8 & 8 & 8 & - & - & - \\
ADG, kg & 0.995 & 0.964 & 0.931 & 0.0134 & 0.005 & 0.949 \\
ADFI, kg & 2.917 & 2.804 & 2.702 & 0.0323 & $<0.001$ & 0.899 \\
G:F & 0.341 & 0.344 & 0.345 & 0.0032 & 0.416 & 0.814 \\
Final BW, kg & & & & & & \\
d 77 & 138.24 & 135.76 & 132.93 & 1.1626 & 0.004 & 0.902 \\
\hline
\end{tabular}

116 Improving the feeding value of corn stover to enhance cattle performance in a backgrounding phase. K. Nenn 1,*, P. H. V. Carvalho' ${ }^{2}$, E. Mousel ${ }^{3}$, G. A. Bridges ${ }^{3}$, S. L. Bird ${ }^{3}$, T. L. Felix ${ }^{2}$, A. DiCostanzo ${ }^{1},{ }^{1}$ University of Minnesota, Saint Paul, ${ }^{2}$ University of Illinois at Urbana-Champaign, Urbana, ${ }^{3}$ University of Minnesota, Grand Rapids.

The objective of this study was to investigate the effects of alkali-treatment $\left(\mathrm{CaOH}_{2}\right)$ or water addition to corn stover on in situ DM and NDF digestibility (DMD and NDFD) and growth performance of cattle during a backgrounding phase. Fifty-one lightweight Angus steers (average BW $197 \mathrm{~kg}$ ), fed individually in a Calan-Broadbent feeding system, were randomly allotted to 1 of 3 corn stover ( $30 \%$ of diet DM) feeding treatments: 1) dry, untreated corn stover ( $85 \% \mathrm{DM}), 2)$ corn stover treated with $\mathrm{CaOH}_{2}$ at $6 \%$ inclusion (as-fed basis) and water hydrated to $50 \% \mathrm{DM}$, or 3 ) corn stover water hydrated to $50 \% \mathrm{DM}$. Legume-grass silage (15\%), dry rolled corn (25\%), dry distillers grains and solubles $(25 \%)$, and a vitamin and mineral supplement (5\%) constituted the balance of the diet DM. Steers were fed once daily at $0600 \mathrm{~h}$, and orts were weighed and sampled during this time. Body weight was measured on d 1and 49 after withdrawing feed and water for $16 \mathrm{~h}$. In situ DMD and NDFD were measured at 12, 24, 36, and $48 \mathrm{~h}$ in 2 ruminally cannulated steers. Averaged over time, DMD and NDFD differed ( $P$ $<0.05)$. Digestibility of DM and NDF of calcium hydroxide-treated corn stover were greater $(38.1 \%$ and $45.7 \%)$, that of untreated corn stover was intermediate (28.1\% and $32.8 \%)$, and that of water-treated corn stover was lowest $(16.9 \%$ and $15.5 \%)$. Similar results were observed using an in vitro gas production batch culture. Cattle fed water-treated corn stover consumed more $(P<0.05)$ feed DM and had faster rates of gain $(P<0.05)$ than those fed untreated corn stover. Cattle fed calcium hydroxide-treated corn stover had intermediate rates of gain that were similar $(P>0.05)$ to those of cattle fed water-treated or untreated corn stover. Feed conversion was not affected $(P>0.05)$ by corn stover treatment. An alternative to alkali-treatments, albeit when forage supply is not limiting, may be simple water addition as cattle fed water-treated corn stover gained weight more rapidly while consuming more DM.

Key Words: alkali-treatment, corn stover, gains

doi: 10.2527/msasas2016-116 